\title{
LOS CONFLICTOS ETNOAMBIENTALES DE "PAMPA COLORADA" Y “El TATIO” EN EL SALAR DE ATACAMA, NORTE DE CHILE. PROCESOS ÉTNICOS EN UN CONTEXTO MINERO Y TURÍSTICO TRANSNACIONAL
}

\author{
Paola Bolados García
}

\section{$*$ Introducción}

Resumen

En el segundo lustro del 2000, las poblaciones indígenas del salar de Atacama (norte de Chile) fueron protagonistas de dos emblemáticos conflictos conocidos como "Pampa Colorada" y "la Defensa del Tatio". Analizamos en este artículo las relaciones entre los procesos étnicos de los años noventa experimentados en el salar y las economías transnacionales de enclave, como la minería y el turismo, que ingresaron en ese mismo período a esta región, producto de un cambio en el marco jurídico y legal impuesto durante el régimen militar. Nos aproximamos a la complejidad socioétnica del salar desde una perspectiva histórica y antropológica con el fin de etnografiar las formas hegemónicas y resistidas de una globalización transnacional, la cual -y ésa es nuestra tesis central- proviene de las presiones por constituir y reivindicar simultáneamente al salar de Atacama como territorio indígena, minero y turístico.

Palabras claves: globalización transnacional - atacameños - minería y turismo - salar de Atacama.

\begin{abstract}
During the second half of the 2000 s, indigenous populations of the Salar de Atacama (Northern Chile) played a main role fighting in two significant environmental conflicts known as "Pampa Colorada" and "The Tatio Defense". Taking into account these historical events, this paper analyses the relationships amidst ethnic processes experienced by the Salar during the 90 s and transnational economies embedded in a complex phenomena of production such as mining and tourism. These production processes were installed there as a consequence of changes within the legal framework during the military regime. From historical and anthropological perspectives, the author of this paper seeks a different approach to understand the social and ethnic complexity of the Salar, doing ethnography of hegemonic and resistance forces which compose a significant part of the transnational globalization. The main thesis of this paper is to reveal the pressure struggles between agenda and structure with the purpose of establishing mechanisms to vindicate the Salar de Atacama as an indigenous and mining/tourist territory at the same time.
\end{abstract}

Key words: transnational globalization - atacameños - mining and tourism - salar de Atacama.
A fines del siglo XX y comienzos del actual, la región del salar de Atacama (norte de Chile) es objeto de nuevas y variadas intervenciones estatales y transnacionales ( $\mathrm{Fi}$ gura 1). Éstas tuvieron como origen una política indígena y multicultural desplegada por el Estado chileno, luego de retornada la democracia en el país. Sus objetivos eran dar respuesta a los compromisos asumidos por los gobiernos democráticos de la Concertación en el Acuerdo de Nueva Imperial del año 1989, respondiendo de esta manera a las demandas de reconocimiento y legitimidad jurídica defendidas por las organizaciones indígenas. Este proceso se enmarcó en un contexto internacional favorable, que promovió los derechos culturales y territoriales de los pueblos indígenas. A su vez, éstos fueron acogidos en la agenda de organismos multilaterales como el Banco Interamericano de Desarrollo -BID-y el Banco Mundial a través de lo que llamaron propuestas de desarrollo con identidad. En consecuencia, parte de la agenda investigativa nacional estuvo orientada a respaldar científicamente la existencia de las poblaciones originarias, así como también otorgar validez histórica y social al paradigma de la interculturalidad y la diversidad cultural. Con estas acciones, el Estado de Chile intentó abandonar las teorías de la integración y la homogeneidad del Estado-nación imperantes en el siglo anterior (Boccara y Seguel 1999).

En este contexto se aprobó la Ley Indígena del año 1993, que creó la Corporación Nacional de Desarrollo Indígena (CONADI) y espacios territoriales de distribución de

Recibido: julio 2014. Aceptado: octubre 2014.

1 Instituto de Historia y Ciencias Sociales, Convenio de Desempeño de las Humanidades, Artes y Ciencias Sociales de la Universidad de Valparaíso. Av. Blanco 1215, Dpto.101, Valparaíso, CP 2340000, Chile. Email: paola.bolados@uv.cl 


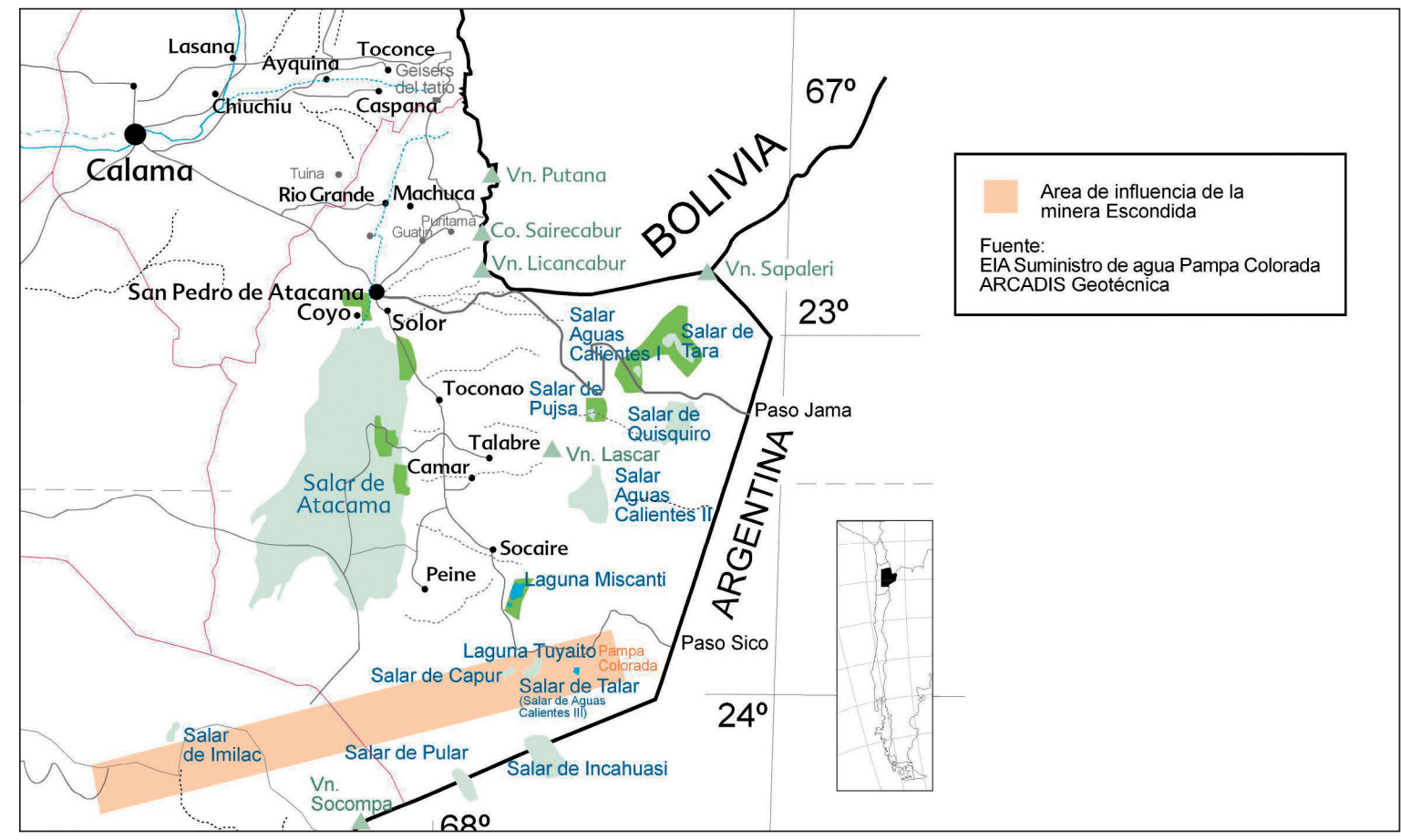

Figura 1. Mapa de comunidades del Alto Loa: Chiu Chiu, Lasana, Ayquina, Caspana, Toconce; y del salar de Atacama: Río Grande, Machuca, San Pedro de Atacama y sus ayllus, Toconao, Talabre, Camar, Socaire y Peine. Área de influencia de Minera Escondida en Pampa Colorada y Géiseres del Tatio.

los recursos estatales hacia las poblaciones originarias, denominados Áreas de Desarrollo Indígena (ADI). Estas medidas coincidieron con otras acciones de carácter estatal/multilateral, dirigidas a poner en valor las culturas e identidades indígenas nacionales bajo las denominadas políticas de patrimonialización (Ayala 2007). El intenso esfuerzo puesto en desarrollar la política multicultural y patrimonial en el Chile democrático de los años noventa, significó no obstante, una desatención a otras problemáticas y fenómenos que irrumpieron en ese mismo período, como fueron la expansión de la minería y el turismo transnacional en regiones de especial interés económico como es el salar de Atacama. Situación que activó procesos migratorios que tensionaron el ambiente social en relación al acceso y control de los recursos tanto naturales como culturales disponibles en el territorio. Entre los trabajos que se hicieron cargo de esta problemática, puede nombrarse el de la antropóloga Marinka Núñez el 2003 en el sector sur del salar, principalmente en las comunidades de Toconao y Peine. Un segundo trabajo es el del antropólogo Francisco Rivera el 2007, quien retomando la problemática identitaria en un contexto neoliberal, buscó analizar las continuidades con la historia minera del siglo XX, así como las rupturas a partir de lo que denomina como el discurso antiflexible de los atacameños. El primero releva las transformaciones más bien micro que la minería del litio ha generado con su incorporación en las localidades, advirtiendo entre sus efectos principales una mayor sedentarización producto de la sustitución de actividades agropastoriles por aquellas vinculadas - directa o indirectamente- a la actividad minera. El trabajo de Rivera en cambio se concentra en los factores macro que presionan sobre el territorio y la co-construcción económica e identitaria del Salar a partir de las elevadas inversiones públicas y privadas de las que es objeto la comuna de San Pedro de Atacama en la última década y media, convirtiéndola en la región con el producto interno bruto (PIB) y el sueldo promedio más alto de Chile. ${ }^{2}$

\footnotetext{
2 La minería en Chile representa casi 20\% del PIB, del cual más del $17 \%$ proviene directamente de la minería del cobre (SERNAGEOMIN 2010; COCHILCO 2010).
} 
Sin embargo, en los últimos años se observa un mayor interés por estudiar los impactos de la minería en las comunidades atacameñas a través de las relaciones que han establecido vía acciones de responsabilidad social empresarial (RSE) y/o convenios directos. Interesados en relevar las dimensiones del poder comunicacional involucrado en los intentos por establecer un escenario de buenos vecinos entre comunidades y corporaciones mineras, así como también las dimensiones éticas y técnicas involucradas, tanto el trabajo de Carrasco (2010) como el de Babidge (2013) se presentan como trabajos pioneros sobre las relaciones de negociación/confrontación entre comunidades indígenas atacameñas y corporaciones mineras. Éstas se revelan siempre como relaciones asimétricas pero significativas en cuanto a sus efectos performáticos, ya sea por discursos y prácticas que apelan a la transparencia, como a través de estrategias de sobrecomunicación que se estructuran a partir de relaciones desiguales. De la misma forma, emergieron los primeros estudios sobre el turismo en el sector del salar dirigidos a analizar la incorporación de los atacameños en esta industria. Estos relevan el turismo como una estrategia de construcción étnica basada en una cultura e identidad reconocida y valorada no sólo simbólica, sino también económicamente por agentes nacionales y transnacionales, pero particularmente por agentes locales indígenas, quienes en el último período iniciaron múltiples experiencias de turismo cultural, etnoturismo o turismo de intereses especiales en el sector del salar (Tagliolini 2010; Bustos et al. 2012).

Este artículo se plantea en continuidad con estos trabajos, buscando contribuir con una aproximación socioantropológica e histórica en el análisis sobre los procesos de construcción étnica en un contexto de globalización transnacional como los experimentados en el salar durante las últimas dos décadas. Procesos que adquieren una fisonomía específica a partir del momento que esta área pasó a formar parte del Estado chileno producto del conflicto bélico con Bolivia suscitado a fines del siglo XIX. Desde entonces, las poblaciones locales de la precordillera comenzaron progresivamente a ser objeto de prácticas gubernamentales luego de varias décadas de presencia de capitales ingleses y norteamericanos en esa región. Este contexto nos permite establecer entonces como hipótesis las relaciones entre construcciones identitarias y economías de enclave como la minería y el turismo en una región estratégica para la expansión capitalista del Chile republicano. Impactos que no sólo modificaron la cartografía nacional y sudamericana, sino también tuvieron efectos sobre las poblaciones locales y sus estrategias territoriales para contestar los imaginarios impuestos al paisaje natural y cultural del salar. La pregunta que nos surge entonces es ¿cómo etnografiar estos procesos de globalización transnacional en el salar de Atacama? La respuesta nos obliga a instalarnos en nuevos sitios etnográficos en los cuales fluyen las dinámicas y relaciones entre agentes locales -indígenas y no indígenas-, regionales, nacionales y transnacionales. Es en los espacios de comunicación y relación entre estos agentes que aparecen las representaciones e imaginarios compartidos y a veces confrontados y cuya lógica responde a un contexto y una cosmovisión específica. Estos espacios a veces tienen como lugar las reuniones de la comunidad indígena, así como los organismos estatales y su agenda programática que tiene a cargo la implementación de las políticas en arenas como la minería y el turismo (secretarías regionales de minería, economía, medio ambiente y turismo principalmente). De la misma forma, éstas nos demandan realizar trabajo de campo en las corporaciones mineras nacionales y transnacionales que implementan acciones de responsabilidad social a través de fundaciones y áreas específicas a cargo de relaciones con las comunidades donde se encuentran realizando faenas y en las cuales despliegan su visión del desarrollo sustentable, la cultura y el medio ambiente. ${ }^{3}$ A las múltiples formas de intermediación local-global a las cuales refiere (Mato 2000:152), es preciso en el caso del salar de Atacama en Chile atender especialmente el protagonismo de los agentes regionales, quienes han cumplido un papel relevante como mediadores entre lo global y lo local, a la vez como intermediarios dentro de la confusa y sutil división entre lo público y lo privado. Como agentes locales designamos tanto a las comunidades atacameñas que reivindican el territorio como un territorio indígena, así como otras organizaciones y movimientos de actores no indígenas como las

\footnotetext{
3 Algunos de estos eventos convertidos en sitios etnográficos fueron los seminarios organizados tanto por la Secretaría Regional del Medio Ambiente como también la de Minería durante el 2012, uno de ellos en el marco del proyecto sobre Evaluación de Servicios Ecosistémicos que actualmente se realiza en el salar de Atacama y al cual me refiero en una parte de este trabajo.
} 
juntas de vecinos, asociaciones de turismo, municipio, organizaciones sociales; $y$ que por su trayectoria muestran interés por participar de la vida local más allá de las actividades económicas, políticas o sociales que realizan. Nos referimos como agentes regionales a personas $e$ instituciones que provienen de la región de Antofagasta a la cual el salar de Atacama pertenece administrativa y políticamente, y lugar donde se concretan las acciones de agentes nacionales y globales que quieren desplegar acciones en el salar. Agentes nacionales alude principalmente a organismos y personas individuales del Estado y privados que despliegan actividades en la comuna de San Pedro de Atacama pero que no residen en forma permanente en la zona, no obstante tengan una participación relevante en las tomas de decisiones locales como de inversión en el salar. En ellas también incorporamos a las ONG nacidas en el país, como el Observatorio de Derechos Humanos o el Programa Chile Sustentable, así como otros actores nacionales no gubernamentales que provienen principalmente del centro del país e intervienen en el salar. Agentes transnacionales en cambio, lo utilizamos para referirnos a organismos internacionales como la ONU, la UNESCO, corporaciones mineras u operadores turísticos transnacionales, así como organizaciones no gubernamentales internacionales. $^{4}$

4 Entre los agentes transnacionales que destacan por su presencia en el salar podemos nombrar al Programa de Naciones Unidas y Medio Ambiente -PNUMA- que actualmente desarrolla el proyecto ECOSERV sobre Evaluación de Servicios Ecosistémicos, el programa internacional Atacama Large Millimeter Array -ALMA- de la empresa transnacional de astronomía European Southern Observatory -ESO-, que acaba de terminar de construir el centro de observación de radiotelescopios más grande a nivel mundial en el sector de Chajnantor, aproximadamente 65 $\mathrm{km}$ al este de San Pedro de Atacama. En este grupo también podemos incluir a las agencias de turismo internacional que tienen operaciones en el salar de Atacama, así como la Fundación Minera Escondida (FME) de la australiana BHP Billiton. Entre otras corporaciones mineras transnacionales presentes en el salar ya sea por tener concesiones mineras o derechos de aprovechamiento de aguas podemos nombrar a la norteamericana Rockwood Lithium, la canadiense Zaldívar de Barrick Gold, así como Escondida, operada por la australiana BHP Billiton. Cabe destacar también la presencia e injerencia en varias comunidades de la empresa SQM, ex Sociedad Química Minera de Chile (SOQUIMICH), que aunque originalmente es de capitales nacionales, su producción y mercado están dirigidos principalmente al extranjero.

\section{* Complejos culturales transnacionales EN EL SALAR DE ATACAMA}

Los estudios sobre globalización y etnicidad han llamado la atención respecto a la conexión directa entre procesos trasnacionales estimulados por megaindustrias como la minería y el turismo y su impacto en la producción de representaciones e imaginarios. Asimismo, éstos han relevado la participación e involucramiento progresivo de agentes indígenas en redes transnacionales promovidas por estas industrias, constituyendo a nuestro entender complejos culturales que incentivan formas de circulación y comunicación específicas. Ellos fomentan conductas asociativas bajo una perspectiva individualista cuyos efectos tienden a reforzar valores como el autoemprendimiento (Comaroff y Comaroff 2009) erigiendo el paisaje natural y cultural como bienes simbólicos y capitales económicos por excelencia (Bourdieu y Wacquant 2005); asimismo propician reconfiguraciones sociales donde lo étnico es incorporado como factor de desarrollo en un esquema de relaciones de mercado (Yúdice 2008). Las comunidades son tratadas como grupos corporativos a la vez que como clientes exóticos (Bolados 2010) en un contexto de expansión capitalista, donde por un lado y en un contexto indigenizado como el salar, se potencian discursos y prácticas localizadas, las cuales han favorecido que los agentes indígenas avancen en sus demandas de control del territorio y sus recursos naturales y culturales asociados; mientras por el otro, ha legitimado a agentes transnacionales relacionados con la industria de la minería y el turismo como interlocutores válidos en lo que se suele denominar desarrollo local. En consecuencia, la configuración de las industrias de la minería y el turismo en complejos culturales transnacionales en el contexto atacameño, se traduce en la existencia de discursos y prácticas de confrontación que denuncian a estas actividades como depredadoras de la cultura atacameña - población indígena numéricamente más importante de la región del salar-comuna de San Pedro de Atacama-, a la vez que desde una postura más bien de negociación, se las entiende como fuentes de desarrollo local en el territorio por las oportunidades de trabajo y capacitación que estas industrias fomentan.

Pero ¿qué tipo de circulaciones de ideas, personas y materialidades actualmente generan estas actividades 
en la región del salar de Atacama, norte de Chile? y ¿cómo el turismo y la minería se constituyen finalmente en complejos culturales trasnacionales? El concepto complejos culturales trasnacionales lo tomamos de la noción de complejos de relaciones transnacionales propuesto por Daniel Mato (2000 y 2004), a través del cual intenta explicar las configuraciones complejas y dinámicas en las cuales hoy se establecen relaciones entre agentes locales, regionales, nacionales y transnacionales en un espacio social determinado. Tomando esta idea y proyectándola al campo de los estudios sobre etnicidad y globalización en contexto de desarrollo neoliberal, consideramos interesante extender su aplicación a fin de observar las actividades de la minería y el turismo como complejos trasnacionales, cuya producción cultural impacta y define diversas configuraciones de circulación y movilidad entre personas, ideas y materialidades en la región del salar de Atacama, norte de Chile. Nos interesa relevar las dimensiones globalizantes y transnacionalizadoras de estas actividades, considerando que en la dinámica actual de la región del salar, éstas, aun con trayectorias muy diversas, muestran vinculaciones intrínsecas en torno a la configuración simultánea de esta región como una región indígena, minera y turística en la nueva cartografía del capitalismo actual. La intensidad, extensión y velocidad que adquieren las circulaciones tradicionales en las últimas tres décadas, revelan una dinámica de dimensiones y alcances desconocidos, mostrando la complejidad y heterogeneidad en la cual se produce lo local y lo global (Boccara 2000; Beck 1998). Conceptos como globalización y transnacionalización son entonces para nosotros en sí mismos objeto de exploración etnográfica. A través de las prácticas y discursos de los agentes definidos como locales, regionales, nacionales y transnacionales estudiamos ambos procesos como conceptos producidos culturalmente en contextos históricamente específicos. En particular, nos interesa debatir el estatus teórico de estos conceptos a partir de su comprensión como formas de contestación a procesos de localización y nacionalización, respectivamente (Boccara y Ayala 2011). Intentamos de esta forma, superar las visiones fetichistas que demonizan o bien apologizan respecto a estos procesos y sus efectos en los agentes sociales, como también las visiones reduccionistas que privilegian una u otra dimensión específica (Mato
2000: 149). Retomando los aportes de Mato, estudiamos la globalización no como un proceso abstracto ni desterritorializado, sino como un proceso de dimensiones múltiples situado históricamente en espacios y actores concretos, donde la producción social de las representaciones es resultado de diferencias, negociaciones y conflictos entre agentes sociales locales, regionales, nacionales y transnacionales. Estas redes y eventos se constituyen en espacios de intercambios, aprendizajes, coproducción y disputas (Mato 2004: 69-74). En un espacio relacional asimétrico con actores de capitales claramente desiguales, las disputas por la posesión de los recursos materiales y simbólicos en que participan a la vez comunidades indígenas, organizaciones gubernamentales nacionales y regionales, así como agentes globales y organizaciones no gubernamentales, revelan un campo tensionado y en permanente definición. Nuestra atención se centra entonces, en las formas contestadas y reelaboradas que actualmente adquieren los actuales procesos de etnicidad en un contexto de globalización transnacional (Mato 2000:160). Se da entonces un desplazamiento de la retórica indigenista y multicultural impuesta desde el Estado y sus aliados multilaterales, hacia una retórica medioambientalista y de derechos indígenas proveído por agentes transnacionales, cuyos contenidos al menos en el caso atacameño, incorporaron históricas demandas de inclusión social.

Nos referimos al proceso de globalización transnacional como un conjunto de fenómenos asociados a una economía neoliberal que se reconfigura y obliga a un nuevo rol del Estado y la sociedad, así como de los agentes globales, cuyas acciones y discursos impactan sobre los desplazamientos y movilidades no sólo de personas, sino también de ideas y materialidades que circulan a una velocidad antes desconocida. Rutas e itinerarios que adquieren una fisonomía particular con las nuevas experiencias del tiempo y el espacio provistas por las tecnologías de la información (Castell 2005), las cuales convergen con una abstracción de las relaciones económicas producto de la financiarización de la economía capitalista (Harvey 2008).5 Los estudios sobre

5 Como este autor sostiene: "Precisamente porque el capitalismo es expansivo e imperialista, cada vez más áreas de la vida cultural se incluyen en la lógica de la circulación del capital y del dinero. 
globalización han tendido a reforzar la idea de que el Estado ha debilitado su poder para intervenir en los procesos locales, regionales y nacionales. Gran parte de estos análisis plantean un escenario donde los agentes locales aparecen presionados de manera unilateral por agentes globales y/o trasnacionales. Sin embargo, estas visiones descuidan que pese a la confluencia de agentes con poderes y campos de influencias desiguales en contextos específicos, éstos logran posicionarse en disputas complejas como son hoy en día las luchas por los recursos naturales y culturales. En torno a estos recursos y su apropiación por parte de diversos agentes, se están produciendo nuevas redes y asociatividades que no obstante la asimetría de los recursos simbólicos y materiales de cada uno de ellos, revelan un escenario dinámico y complejo, que pasa por momentos de alianzas y negociaciones como también por períodos de luchas y conflictos. Aunque reconocemos que las múltiples interpretaciones y énfasis sobre estos procesos se concentran en las dimensiones económicas, consideramos que éstas trascienden el campo económico, mostrando impactos relevantes en las estructuras de las relaciones sociales e identitarias, como las que se produjeron en los últimos años entre las poblaciones indígenas en Chile. De allí que sea preciso resituar estos impactos de la globalización a la vez que historizarlos en su contexto: el lugar del salar de Atacama en el imaginario colonial, republicano y su configuración como espacio geográfico y geopolítico estratégico para el proyecto nacionalizador del Chile liberal del siglo XX.

\section{Aproximándonos a la complejidad socioétnica del salar de Atacama}

El salar de Atacama, región de Antofagasta en el norte de Chile, desde tiempos prehispánicos reveló ser un paisaje natural y cultural complejo. Como lo registran estudios arqueológicos e históricos, se constituyó desde tiempos prehispánicos en un espacio de intercambios e interacciones entre grupos culturales diversos que debieron desplegar estrategias de adaptación en

En realidad esto ha dado lugar a numerosas reacciones que van desde la cólera y la resistencia hasta la sumisión y la valoración [...] Pero la ampliación y profundización de las relaciones capitalistas con el tiempo es, sin duda, uno de los hechos más singulares e incontestables de la geografía histórica reciente" (Harvey 2008:376). nichos ecológicos heterogéneos. ${ }^{6}$ Asimismo, esta región se erigió como un auténtico oasis en medio de un extenso y despoblado desierto, según los relatos y travesías narradas por conquistadores y misioneros que pretendieron ingresar al reino de Chile por el inhóspito y desafiante desierto de Atacama durante la colonia.? Tanto vestigios arqueológicos como fuentes históricas -coloniales y republicanas- dan cuenta de la importancia científica, geopolítica y minera de esta región surandina, relevancia que se fue consolidando al punto de configurarse en un territorio de luchas entre las nacientes repúblicas del Perú, Bolivia y Chile a finales del siglo XIX, cuando se producen los hechos de la Guerra del Pacífico y cuyas consecuencias generaron una radical modificación a la cartografía regional de ese momento. Aunque la guerra definió límites hacia 1884, éstos fueron recién del todo esclarecidos hacia las primeras dos décadas del siglo XX, cuando la región del salar fue ratificada como territorio chileno y la Puna de Atacama como territorio argentino (Sanhueza 2001). Vale decir, la presencia del Estado se hizo tangible en esta zona particularmente a finales del ciclo salitrero, cuando la actividad cuprífera se expandía con la mina de Chuquicamata. Manifestación palpable de esta presencia fue la incorporación de la escuela pública en la década del treinta del siglo pasado, las juntas de vecinos en los años cincuenta, la creación de instituciones como la Corporación de Fomento (CORFO) en los sesenta, y

\footnotetext{
6 Las nociones de circulación y movilidad andinas se encuentran presentes en gran parte de la literatura especializada tanto arqueológica como histórica. No obstante para nuestra región de estudio, destacaremos las ideas de verticalidad (Murra 1996) y complementariedad ecológica (Hidalgo 2004; Martínez 1998) como centrales para comprender las formas de ocupación y asentamiento de los grupos y comunidades agropastoras del salar. En particular, éstas nos permiten analizar la dinámica histórica de esta área a partir de la necesidad de asegurar recursos en un contexto desértico donde el agua cumple un papel preponderante para la vida y reproducción de las poblaciones que allí han habitado. Asimismo, este modelo de circulación marcado por la dispersión y extensión, ha definido un sistema de relaciones interétnicas e interdigitadas, efectivizadas por alianzas y redes de parentesco y compadrazgo entre grupos que hoy pertenecen al sur de Bolivia, noroeste argentino y norte de Chile, y del cual existe amplio registro documental.

7 La crónica colonial más temprana donde se encuentran estas representaciones es la de Bibar (2001 [1558]) y también en el libro de Extirpación de Idolatrías de Álvarez (1998 [1588]).
} 
hacia finales de los setenta y durante los ochenta bajo el régimen militar, con el ingreso de nuevos actores transnacionales producto de un cambio de legislación que estimuló la inversión extranjera y la privatización de los recursos naturales. El salar de Atacama el año 1980 experimentó dos importantes acontecimientos: pasó a formar un centro administrado autónomo a través de la creación del Municipio de San Pedro de Atacama y ese mismo año fallece una de sus figuras emblemáticas; el sacerdote y arqueólogo belga Gustavo Le Paige, quien ejerció hasta ese momento un rol político, religioso y científico fundamental. Este nuevo distrito agrupó a las comunidades más próximas del salar y favoreció la construcción de un espacio donde elaborar demandas sociales que progresivamente adquirieron elementos de un discurso étnico reivindicativo. Durante estos años ingresaron al salar la minería del litio a través de dos empresas: la entonces conocida como Sociedad Chilena del Litio y la Sociedad Química Minera de Chile (SOQUIMICH), mientras que el holding hotelero Explora realizó compras extensas de terrenos en diversos sectores del salar. Estos y otros factores, como la apropiación y reelaboración realizada por dirigentes indígenas atacameños de una evidencia material e histórica de una cultura atacameña a partir del trabajo de Le Paige, establecen las condiciones necesarias para un proceso de construcción étnica como el experimentado en el salar de Atacama en la década de los años noventa.

La incorporación de las industrias nacionales y transnacionales de la minería y del turismo a la región, así como las propuestas multiculturales y patrimoniales implementadas por el Estado en ese mismo período, se interceptarán con demandas históricas de inclusión social de los pueblos hasta ese momento conocidos como "del interior" y/o precordilleranos que se identificaron como licanantay (que significa 'nuestro pueblo' en lengua kunza) o atacameños como fueron reconocidos finalmente por la legislación indígena del año 93. La conjunción de estos elementos devino en activos procesos de identificación de carácter socioétnico entre los grupos culturales locales, los cuales se estructuraron en sus inicios bajo la díada "atacameños" versus "afuerinos". La masiva llegada de grupos no indígenas, nacionales e internacionales a la región del salar y su incorporación en espacios de la localidad tuvieron efectos sobre la estructura social, que de relaciones de subordi- nación pasiva frente a los "afuerinos invasores" pasaron a períodos de confrontación, los cuales tuvieron como punto máxime los intentos de la quema de la iglesia de San Pedro, del museo y también del municipio local. Más tarde comenzaron una etapa marcada por relaciones de reconocimiento y colaboración frente a ciertas luchas, como las que se desataron el año 2007 en torno a las solicitudes de extracción de aguas en el sector Pampa Colorada por la empresa minera transnacional Escondida, así como el 2009 por las exploraciones geotérmicas realizadas en el sector turístico Géiseres del Tatio. Como analizaremos más adelante, estos dos proyectos configuraron la antesala de un escenario de conflicto entre agentes locales, regionales, nacionales y transnacionales, los cuales se vieron obligados a establecer y redefinir relaciones así como también a desplegar diversas estrategias comunicacionales a fin de concretar sus demandas y/o intereses.

A finales de los años noventa encontramos en el salar de Atacama un escenario de transición. De una subárea caracterizada por una circulación andina tradicional cuyos antecedentes arqueológicos e históricos en la región circumpuneña están marcados por actividades como el tráfico de caravanas, de mulas, el tráfico de pescado y una intensa arriería; los grupos agropastores del salar de Atacama desde la República en adelante se vieron presionados cada vez más a incorporarse a lo que podríamos definir como una circulación andina transnacional, cuyos antecedentes se encuentran en la explotación de la mina de plata de Caracoles y el ciclo salitrero a fines del siglo XIX, la expansión cuprífera durante el siglo $\mathrm{XX}$ en torno a Chuquicamata, y luego en la década de los años 1980 y1990 con la incorporación de múltiples agentes -nacionales y transnacionales- provenientes de la minería y el turismo. La incorporación de estos agentes tuvo como escenario las medidas neoliberales que se implementaron en Chile por la dictadura militar a mediados de los años setenta, la cual se erigió sobre instrumentos legales como la Ley de Inversión Extranjera Directa (IED) del año 1976 -que facilitó y promocionó el ingreso de inversiones extranjeras al país-, la Constitución nacional del año 1980 que consagró el principio de propiedad privada, el Código de Aguas del año 1981 que separó el principio territorial de unidad entre los recursos hídricos y de suelo; y el Código Minero del año 1982, el cual abrió y expandió aún más la industria 
minera a las corporaciones trasnacionales. Medidas que tuvieron como efecto un crecimiento progresivo de la demanda energética en general, e hídrica en particular, afectando de manera directa a las poblaciones originarias de Chile, particularmente las del norte donde se encuentra la población atacameña (Yáñez y Molina 2008).

Parte importante de estos cambios fueron recogidos en el Censo 2002, el cual mostró un crecimiento demográfico significativo respecto del período anterior. Este reveló una presencia de población no indígena que en algunas comunidades superó el 50\%, como fue el caso de Peine y San Pedro de Atacama (INE 2002). Este fenómeno sociodemográfico es también recogido en el estudio realizado por la ONG Corporación RIDES el año 2005 sobre "Bienestar Humano y Manejo Sustentable en San Pedro de Atacama-Chile" en el marco de la Evaluación Ecosistémica del Milenio, constatando la ubicación de la comuna en uno de los principales destinos turísticos del país y del extranjero, situación que anualmente trae a cerca de 50 mil visitantes de todas partes del mundo. ${ }^{8}$ Simultáneamente, el salar es parte de una provincia -el Loa- y una región-Antofagasta- donde se produce más del 60\% de la producción minera del país, estimulando intensos y permanentes flujos migratorios nacionales e internacionales relacionados con esta actividad. Como señalamos, de una población originaria históricamente caracterizada por una circulación andina tradicional de carácter transfronterizo hacia el noroeste argentino y actual sur de Bolivia, pasamos en estas últimas décadas a una circulación andina transnacional, incentivada por flujos internacionales generados entre otros, por la actividad minera y turística, así como por los diversos organismos estatales encargados de implementar políticas públicas. A estos componentes que forman parte de la dinámica del salar es preciso in-

\footnotetext{
8 El proyecto es un programa internacional cuyo objetivo fue evaluar en un período de cinco años (2001-2005) la capacidad de los ecosistemas para seguir proporcionando bienestar humano y vida en la tierra, considerando la enorme y creciente presión que han sufrido en los últimos 50 años. El programa es incentivado desde organizaciones como las Naciones Unidas con financiamiento del Banco Mundial y el Fondo para el Medio Ambiente, países donantes y otras fundaciones privadas. Ésta a su vez pretende contribuir a alcanzar los Objetivos del Milenio de las Naciones Unidas y el Plan de Implementación de la Cumbre sobre Desarrollo Sustentable realizada el 2002 en Johannesburgo (RIDES 2005: 6).
}

corporar las acciones realizadas por instituciones científicas tanto nacionales como internacionales, a través de disciplinas como la arqueología, la antropología, la geología y más recientemente la astronomía, las cuales en sí mismas fomentan circuitos de movilidad específicos. En consecuencia, los procesos de etnicidad atacameños debemos comprenderlos como procesos crecientemente complejos y dinámicos resultado de diversos agentes (no sólo indígenas) y de heterogéneos factores (sociohistóricos, políticos, económicos y culturales) que han estado presentes en la producción de las representaciones e imaginarios del salar de Atacama, así como en la construcción de sus identidades y territorialidades.

El cambio de siglo se destacó, sin embargo, no sólo por la intensa política indígena y patrimonial desplegada por el Estado chileno, o por la incorporación de agentes globales provenientes de la minería transnacional; sino que en ese mismo lapso se produjo lo que se conoció como el "boom turístico" (Bustos 2005). De un período entre los años 1960 y 1980, marcado por la migración de los habitantes de los poblados a la ciudad de Calama, se dio inicio un proceso de retorno y reocupación del territorio, no sólo de sus habitantes originarios tradicionales, sino también un número cada vez mayor de población que ingresó a la comuna a desarrollar experiencias turísticas de diversos tipos. Aunque muchos relacionan el inicio del boom turístico con la instalación del hotel Explora a mediados de los años noventa, otros cercanos a Le Paige consideran que éste partió con uno de los congresos de arqueología realizados en la década de los ochenta y que "... trajo a muchas personas de todo el mundo. De ahí nunca más paró la venida de turistas". 9 Explora fue el primer proyecto de hotel cinco estrellas en el salar, el cual ya había iniciado actividades en la década de los ochenta a través de la compra de extensas áreas de terrenos en sectores emblemáticos como es el ayllu de Yaye y en el sector termas de Puritama, donde esta empresa adquirió aproximadamente 8446,2 hectáreas. Más tarde se conoció que este holding había comprado terrenos en otras localidades del salar. El proyecto del hotel se presentó como una oportunidad de trabajo para los atacameños, así como un proyecto de relevancia arquitectónica y medioambiental por el uso de múltiples energías

\footnotetext{
9 Entrevista realizada a la dirigente atacameña Ada Aramallo en San Pedro de Atacama, febrero de 2012.
} 
no convencionales como la solar, reciclajes de basura, entre otros. Sin embargo el emplazamiento del proyecto en una delicada zona arqueológica desplegó múltiples relatos sobre saqueos, profanaciones y diversas historias locales relacionadas con el patrimonio allí encontrado. $\mathrm{Al}$ impacto paisajístico se le sumó el impacto sociocultural en tanto se lo percibió inicialmente como un transgresor de la cultura local, así como un generador de relaciones laborales desiguales y de explotación. No obstante, las relaciones de tensión entre las comunidades y el hotel no se expresaron nunca en conflictos explícitos. Acuerdos de colaboración económica de la empresa con el Hogar Andino, administrada por el Consejo de Pueblos Atacameños, y que recibe a estudiantes de las localidades del Alto Loa y el salar para continuar los estudios medios en Calama, permitieron manejar medianamente estas tensiones hasta el año 2007, cuando el Consejo de Pueblos Atacameños decidió denunciar judicialmente a Explora S.A. por adueñarse de aguas medicinales de uso ancestral en las termas de Puritama. Este conflicto se desató cuando el hotel había ya logrado instalarse a nivel local y modificar en parte su rol de explotador, mostrando una incorporación cada vez más activa de trabajadores locales dentro de su estructura organizativa. Incluso comienzan a incorporarse los primeros guías atacameños y el hotel inicia actividades pedagógicas en algunas localidades a través de talleres de inglés y otras formas de colaboración. Lo cierto es que cuando se produjo el conflicto entre la empresa y la organización indígena, no tuvo la repercusión esperada y más tarde el Consejo de Pueblos Atacameños supo del fallo que favoreció a Explora, desestimando la posibilidad de ir a instancias internacionales. No obstante, y mientras se desataron estas tensiones, en el transcurso de la primera década de este nuevo milenio ingresó un torrente de nuevos hoteles, entre ellos otros tres de cinco estrellas y una multiplicidad de otras empresas y agencias turísticas nacionales e internacionales..$^{10} \mathrm{El}$ hotel expandió sus operaciones y

${ }^{10}$ El 2012 SERNATUR publica los lugares registrados para alojamiento, alcanzado un número de 98. El primero en establecerse en la localidad en los años ochenta es la Hostería de San Pedro. Luego le seguirán iniciativas como la agencia Atacama Desert y el Lodge Terrantai, perteneciente a un empresario atacameño. Luego nacieron durante los noventa el hotel Tulor (perteneciente a una arqueóloga), el hotel Kimal (de otro empresario de la región), el hotel Aldea (de un ex consejero regional) y la casa de Don Tomás. En los últimos años llegaron otros hoteles de cinco estrellas estableció estrategias de relación con las comunidades avanzando en torno a construir un área protegida en el sector Termas de Puritama. Esto lo hizo a través de la creación de una fundación cuyo objetivo sería proteger el sector como una reserva para contribuir a "resguardar el patrimonio natural y cultural atacameño". Entre los aspectos más interesantes con las que nació esta iniciativa fue la de generar una línea de investigación en temas de biodiversidad, flora y fauna de esta área, ofreciendo recursos para la realización de investigaciones de pre y postgrado. Sin embargo, la lógica del resguardo conservacionista de esta acción trajo consigo que el acceso a las termas se restringiera al punto que actualmente es uno de los destinos más exclusivos en el circuito turístico de San Pedro de Atacama.

La importancia del turismo quedó sellada en el propio logo institucional del municipio que rezó desde entonces: "San Pedro de Atacama: capital arqueológica, turística y astronómica", pero no obtuvo como respuesta una política destinada a fomentar procesos de planificación y control. Más bien para la población local este proceso se presentó en sus inicios como un avasallamiento de espacios y recursos frente a las cuales mostró un fuerte rechazo y en otros casos, se expresó a través del replegamiento y/o abandono de la circulación de los atacameños por el casco central del pueblo. Todavía algunos pastores recuerdan con nostalgia cuando conducían sus rebaños sin temores por las calles Caracoles, Toconao, Tocopilla, Le Paige y Atienza, las cuales hoy se encuentran ocupadas en gran parte por el turismo nacional y transnacional. Estos antiguos habitantes han sido testigos de cómo el turismo ha aumentado las demandas de recursos energéticos dirigidos a satisfacer los requerimientos de hoteles, restaurantes, así como de transporte, dentro de un localidad con todavía una insuficiente infraestructura vial, y hasta hace poco una no potabilización del agua en todas las localidades, con serios problemas en servicios básicos y alcantarillado. La nula política turística sirvió también para mantener la zona liberalizada para realizar actividades turísticas sin mayores exigencias tributarias

como el Kunza, Alto Atacama y el Awasi. Entre los primeros restaurantes se encuentran Tambo Atacameño, que luego desapareció siendo reemplazado por el internacionalmente reconocido El Adobe, cuyo dueño, un importante empresario, actualmente tiene una cadena de cuatro restaurantes en la localidad. 
y de tipo impositivas. El mercado informal creció así como crecieron también actividades ilícitas asociadas al micro y narcotráfico, constituyéndose en un cordón de entrada para las diversas drogas también vendidas como parte de la oferta turística. Las construcciones de hoteles y hostales demandaron cada vez más cantidad de mano de obra masculina principalmente boliviana, y el rubro de alojamiento y alimentación requirió de mano de obra femenina. Los más osados se animaron a iniciar pequeños negocios familiares en cocinerías alternativas, los cuales aumentaron correlativamente con los restoranes exclusivos que inundaron el centro de la localidad. La demanda por estos locales aumentó al punto que los arriendos se elevaron a precios irrisorios, al tiempo que el mercado inmobiliario generó un aumento de precios de los terrenos al mismo ritmo. El turismo, sin embargo, fue proporcionando cada vez más espacios para las economías locales, las cuales de maneras diversas y bajo heterogéneas formas, se vieron animadas a insertarse en alguna parte de la cadena productiva, aprovechando las propuestas de capacitación y proyectos de desarrollo promovidos por el Estado y las empresas privadas. Entre éstas tuvieron especial importancia las actividades de fundaciones como la de Minera Escondida (FME), que desde el año 1997 fue desplegando programas productivos ampliándose en el último tiempo a proyectos relacionados al turismo.

Tanto la expansión bulliciosa del turismo como la expansión algo más silenciosa de la minería, fueron modificando no sólo la estructura económica local, sino generando transformaciones sustanciales en las estructuras sociales, productivas y rituales de las comunidades del salar, las cuales dejaron de ser simplemente industrias económicas foráneas para configurarse en complejos transnacionales de producción cultural. Esto debido a que ambas fueron incorporando la dimensión étnica y cultural como eje central de sus programas y proyectos en el salar. Poco a poco las comunidades atacameñas fueron viendo en ellas cada vez más posibilidades laborales para quedarse y no emigrar, como ocurría hasta hace algunas décadas atrás. Reconversión que no obstante, para varias de las comunidades del sur del salar fue una exigencia luego de que el Estado -durante la década de los años noventa- desplegara restricciones para actividades económicas hasta ese momento relevantes para ellas, como la caza de vicuñas y la artesanía con madera de cactus. El propio liceo técnico creado en los años noventa orientó sus espe- cialidades al turismo y la agricultura, estimulando a los jóvenes a insertarse en estas actividades y prolongar su permanencia en sus localidades. Aun ocupando lugares menos favorables y todavía marginales en la estructura social y económica de estas actividades, fueron creciendo otros negocios asociados: almacenes, cocinerías, transportes, taxis, vulcanizaciones, casas de cambio, centros de internet, pequeños alojamientos, espacios para artesanos locales, miniproductores de miel, cerveza, etc. Todos estos nichos fueron siendo ocupados cada vez más por agentes indígenas. Esta situación generó un desarrollo urbanístico desigual y empobrecedor del patrimonio arquitectónico tradicional de corte colonial (que además es portada de innumerables sitios para vender el destino turístico San Pedro de Atacama), a partir de una serie de poblaciones que se fueron construyendo en la periferia de la localidad claramente bajo otros patrones de construcción urbanos. El mercado de trabajo creció incentivando formas de trabajo desregulado y contratos precarios. Un ejemplo de este desarrollo no planificado es que San Pedro, pese a ser uno de los principales destinos turísticos internacionales y nacionales declarados por SERNATUR el año 2002, recién el año 2011 certificó al primer servicio turístico perteneciente a un empresario atacameño. El crecimiento de esta actividad, a su vez, atrajo una multitud de proyectos de hoteles precarios sin certificación ni autorizaciones, los cuales reciben a los jóvenes trabajadores del turismo o bien a los trabajadores de las empresas subcontratistas que operan en la región. Un panorama que en períodos turísticos altos (como son los meses de diciembre, enero y febrero) generan crisis energéticas que se traducen en reiterados cortes de agua y luz producto del exceso de consumo. Incluso sitios como laguna Chaxas o el sector de las lagunas altiplánicas de Miñiques y Miscanti, que además son coadministrados a través de convenios entre la Corporación Nacional Forestal-CONAF- y comunidades atacameñas, mostraron en ciertos momentos niveles de saturación, problemas con el control de las visitas y en la administración de los recursos.

El turismo y la minería se tornaron así en actividades no sólo económicas, sino espacios de interconexiones sociales e identitarias entre agentes diversos, configurando lo que hemos denominado complejos de relaciones transnacionales. En el caso del turismo, éste sufrió un claro cambio a partir de las propias experiencias turísticas que surgieron 
vinculadas al manejo de sitios en el sistema de coadministración firmados entre el Estado y algunas comunidades atacameñas. La cultura e identidad atacameña reconstruida en ese contexto sirvió como estrategia para agentes indígenas locales que se incorporaron de manera directa y activa en las propuestas de turismo cultural, etnoturismo, turismo comunitario o de intereses especiales, como fueron llamadas las iniciativas desarrolladas en los últimos años por comunidades atacameñas. El turismo lentamente mostró su lado más amable y progresivamente se instaló en el imaginario de los atacameños, incluso de los pastores más antiguos del oasis. Comunidades que hace más de dos décadas habían visto marginalmente los beneficios de la minería, encontraron en el turismo un espacio de desarrollo y una forma de recuperación territorial. Esto quedó en evidencia en el área del salar durante la segunda mitad de la década pasada con los conflictos etnoambientales generados en respuesta a dos proyectos mineros, como fueron las movilizaciones de Pampa Colorada el 2007 y la Defensa del Tatio el 2009. Esto evidenció entre otras cosas el nuevo posicionamiento del turismo a nivel local, así también como su convergencia con procesos de control territorial en torno a una territorialidad indígena que proteger. Asimismo reveló los efectos no esperados de una globalización transnacional multifacética y refractaria, capaz de contener agentes diversos en causas comunes, así como también una plasticidad y pragmatismo para incorporar lenguajes y técnicas variadas en pos de recuperar el control del territorio bajo el discurso del "patrimonio medioambiental".

\section{* El proyecto que enlutó al salar de ATACAMA Y LA CAMINATA POR \\ EL TATIO DE DOS MUJERES LICANANTAY}

Aunque parecieron ser dos conflictos temporalmente diferentes, lo cierto es que corrieron juntos en el transcurso de la primera década de este milenio. Ambos marcaron un clima y un escenario inédito en el salar, por un lado poniendo en el centro de la discusión las disputas por el control de los recursos naturales -principalmente el hídrico-, mientras por otro el de los recursos culturales, entre ellos el de poder determinar su forma de desarrollo en un contexto de reconocimiento promovido por las políticas multiculturales y patrimonialistas impulsadas durante el período postdictatorial en Chile. En medio de estas políticas es que el salar de Atacama fue testigo de los conflictos conocidos como "Pampa Colorada" y "el Tatio". Tanto la actividad minera en el primer caso, como la geotérmica en el segundo, enfrentaron públicamente a agentes locales -indígenas y no indígenas-, regionales, nacionales y transnacionales, quienes configuraron diversas alianzas y mostraron renovadas estrategias organizativas y comunicacionales. A su vez, éstos pusieron en cuestión los compromisos del Estado de reconocer y regularizar estos territorios demandados como indígenas, según lo establecido en la legislación del año 93 y ratificado en el posterior proceso de delimitación de tierras.

El proyecto "Suministro de Agua Pampa Colorada" fue presentado el año 2007 al Sistema de Evaluación de Impacto Ambiental (SIE) por la transnacional cuprífera Minera Escondida Limitada (MEL). ${ }^{11}$ Esta empresa transnacional operada en más de un 50\% por la australiana BHP Billiton, se transformó en una década en la segunda productora a nivel nacional junto a la estatal CODELCO. El proyecto ${ }^{12}$ pretendía obtener aguas subterráneas para sus actividades productivas en un total de $648 \mathrm{~m}^{3}$ (cerca de 1000 litros por segundo), los cuales se obtendrían de una zona denominada Pampa Colorada, a unos $50 \mathrm{~km}$ al

${ }^{11}$ Minera Escondida Limitada -MEL- comienza a operar a inicios de 1990 . Se trata de un empresa operada en más de un 50\% por la australiana BHP Billiton junto a otras como Rio Tinto, la japonesa Mitsubishi y una corporación financiera filial del Banco Mundial. Sin embargo, la historia de esta empresa se remonta a los años ochenta, cuando se realizan las primeras exploraciones que dan como resultado un potente yacimiento de cobre al suroeste del salar. Recién el año 1988 comienza a construirse la mina. Esta empresa es la primera en crear una fundación minera en Chile (1997), período desde el cual tendrá un destacado papel en la asesoría técnica y el financiamiento de proyectos sociales y culturales en la región. Una síntesis de la historia de la minera se puede encontrar en la revista digital Minería Chilena (2012, 377: 15-20).

12 El proyecto Pampa Colorada involucraba una inversión de 300 millones de dólares, el cual tendría 20 años de duración y se construiría en dos años. Entre otras cosas involucraba la contratación de mil trabajadores, la habilitación de campos de pozos de producción, una línea de transmisión eléctrica, dos subestaciones y sus respectivas líneas de distribución, un estanque, una planta inhibidora de corrosión, tubería de conducción de agua por $190 \mathrm{~km}$ hasta la mina, dos estaciones de regulación de presión más sus estanques respectivos, un refugio para los operadores y mantenedores, un minicentro de generación hidroeléctrica (COREMA 2007). 
noroeste de la localidad de Socaire, en la comuna de San Pedro de Atacama. El proyecto de extracción se localizaba en un área de bofedales y vegas asociadas a prácticas de pastoreo en el salar, en su mayoría pertenecientes a la comunidad atacameña de Socaire y se emplazaba cerca de sitios protegidos como la Reserva Nacional Los Flamencos en el sector de las lagunas Miñiques y Miscanti, y de valor paisajístico con potencial turístico como Aguas Calientes II y Laguna Tuyacto I. El proyecto fue recepcionado por el encargado de medio ambiente de la municipalidad, en ese momento un dirigente socaireño, quien con el apoyo de un abogado comienza un proceso informativo sobre el proyecto y el impacto que éste tendría en la comuna. Las gestiones realizadas por ellos despertaron una activa oposición al proyecto de parte de las comunidades del sur del salar -Toconao, Socaire y Peine-, quienes iniciaron juntos una lucha contra su aprobación. El primer acto de rechazo lo manifestaron a través del enlutamiento de las comunidades con banderas negras en sus casas. Este significativo acto tuvo eco en el resto de las comunidades, las cuales solidarizaron y se fueron sumando al punto de atraer el interés de uno de los principales medios de la prensa nacional. Las comunidades atacameñas se articularon rápidamente con otras organizaciones locales no indígenas, quienes su unieron a esta movilización y colaboraron con recursos técnicos y económicos. Asimismo se sumaron organizaciones no gubernamentales como el Observatorio de los Derechos Indígenas -hoy Observatorio de Derechos Ciudadanos-, Chile Sustentable, el Observatorio Latinoamericano de Conflictos Ambientales -OLCA- y el Observatorio de Control para Inmigrantes -OCIM. Las alianzas que se generaron entre agentes, así como el uso de las redes sociales, se constituyeron en un factor de comunicación relevante, creándose blogs específicamente dirigidos a visibilizar el conflicto, así como notas en los diarios, que tuvieron repercusión social. Se creó así un escenario de presión sobre los órganos del Estado que debían pronunciarse respecto al impacto del proyecto. En el transcurso de Pampa Colorada a su vez, aparecieron nuevos actores como las consultoras a cargo del mercado del agua, que en este caso fue Exploraciones Mundo S.A., la cual en ese período realizó varias solicitudes de aprovechamiento de aguas en ese sector mientras el proceso de evaluación ambiental avanzaba.

Sin embargo, el rechazo del proyecto por parte de las comunidades y organizaciones locales no sólo se debió al excesivo volumen de aguas solicitadas, sino también a las insuficiencias de la legislación medioambiental para los fines de protección y reguardo de lo que Ley 19.300 definía como "patrimonio medioambiental". Especialmente en cuanto a las competencias técnicas y neutralidad de la empresa mandante para realizar un Estudio de Impacto Ambiental (EIA). Esto lo hicieron notar los propios organismos del Estado como la Corporación Nacional Forestal-CONAF-, quienes acusaron a la empresa de reducir en su informe el área de influencia del proyecto, el cual se encontraba cercano al sector lacustre protegido por el Sistema Nacional de Áreas Silvestres Protegidas del Estado (SNASPE) en la Reserva Nacional Los Flamencos, dentro de la cual se encuentran las lagunas Miñiques y Miscanti. El documento oficial de evaluación ambiental reveló la heterogeneidad de posiciones del Estado frente al proyecto, mostrando un claro y fundado rechazo por organismos como el Servicio Agrícola y Ganadero -SAG-, la CONAF, el Servicio Nacional de Turismo SERNATUR-, la Dirección General de Aguas -DGA-y la Secretaría Ministerial de Obras Públicas; algunas de las cuales como la DGA denunciaron a la empresa de haber omitido información relevante del área de influencia existente con anterioridad en los años 2004, 2005 y 2006 (COREMA 2007: 85-86). Obviamente y como se esperaba, las instituciones locales como la Corporación Nacional de Desarrollo Indígena -CONADI- y la Municipalidad de San Pedro de Atacama, también se declararon en contra del proyecto.

Se observaron también las deficiencias de la legislación indígena de los noventa para cumplir su deber de proteger las aguas atacameñas específicamente señaladas en el artículo $64 \cdot{ }^{13}$ Estas críticas de las comunidades

\footnotetext{
${ }^{13}$ La Ley 19.253 de 5 de octubre de 1993 en su artículo 64 señala: "Se deberá proteger especialmente las aguas de las comunidades Aimaras y Atacameñas. Serán considerados bienes de propiedad y uso de la Comunidad Indígena establecida por esta ley, las aguas que se encuentren en los terrenos de la comunidad, tales como los ríos, canales, acequias y vertientes, sin perjuicio de los derechos que terceros hayan inscrito de conformidad al Código General de Aguas.

"No se otorgarán nuevos derechos de agua sobre lagos, charcos, vertientes, ríos y otros acuíferos que surten a las aguas de propiedad de varias Comunidades Indígenas establecidas por esta ley sin garantizar, en forma previa, el normal abastecimiento de agua a las comunidades afectadas".
} 
fueron fuertemente declaradas durante el proceso de participación ciudadana que la Ley de Medio Ambiente exige, quedando plasmadas en las llamadas "ponderaciones". Éstas no sólo se dirigieron a cuestionar las limitantes técnicas del estudio presentado por la empresa, sino al conjunto de agentes y legislaciones involucradas. Entre éstas destacan el enojo de una de las comunidades del salar que no fue incorporada en el área de influencia del proyecto, aunque por su territorio pasarían las tuberías, y aunque hubiera un convenio de cooperación firmado el año 1997 entre la comunidad y Minera Escondida. De allí la indignación no sólo por haber sido excluidos de este proyecto, sino por sentirse pasados a llevar en la relación de confianza que habían establecido una década atrás:

"Nuestra propiedad comunitaria está explícitamente "salvaguardada" y "protegida" por los artículos 1, 12, 13, 63, 64 y $3^{\circ}$ transitorio de la Ley 19.253, así como por los artículos $19 n^{\circ} 8$ y 19 $n^{\circ} 24$ de la Constitución del República, los Tribunales de Justicia, los pactos internacionales que establecen... la Convención Americana y la Corte Interamericana. YMEL lo sabe [...] CPor qué no nos contó el Gerente de MEL derechamente su intención de constituir una servidumbre sobre nuestras tierras? Nosotros le dijimos que la comunidad estaba inquieta de que fueran a intervenir. MEL evidentemente ya sabía que iba a hacer pasar su tubo y tendido eléctrico por ellas, pero no nos quiso contestar... ¿Por qué no da cuenta el EIA de la reunión que el gerente de MEL sostuvo con los ancianos, las autoridades y el abogado de la comunidad? ... Nosotros le hicimos ver nuestra situación en términos amistosos, como buen vecino. Lo mismo hemos hecho con otras empresas que, ellas sí, han sabido llegar a acuerdos equitativos con nosotros sobre la base del respeto irrestricto al medio ambiente y a nuestro derecho de propiedad comunitario. Sin dar ningún argumento para ello, el gerente de MEL se negó a hacer lo mismo en tres oportunidades y más. Pensamos que tanto en el EIA como en todo lo que hemos expuesto, BHP Billiton y MEL han contradicho su compromiso global de "respetar los derechos tradicionales de los pueblos originarios" (COREMA 2007: 88).

Las comunidades en esta instancia desplegaron el conjunto de argumentos amparados en las legislaciones sobre derechos indígenas, en el Convenio 169 de la OIT y los diversos pronunciamientos realizados por la Corte Interamericana de Derechos Humanos, así como también otros provenientes de organizaciones internacionales. En sus propias palabras:
"La tramitación administrativa del territorio patrimonial natural y cultural de los atacameños está trabajando a favor de intereses económicos transnacionales en forma flagrantemente discriminatoria... El hecho de que MEL no nos acepte como dueños tradicionales de tierras perfectamente identificadas, es una forma de discriminación que atenta en contra de la declaración de principios que BHP Billiton, MEL y FME se han obligado a respetar. El Estado chileno debe impedir la discriminación étnica que MEL ejerce hacia nuestras comunidades, sus propiedades y cultura hidráulica... El Río San Pedro ha disminuido su caudal en la mitad durante los últimos diez años. De los cerca de 1000 $\mathrm{l} / \mathrm{s}$ que se le midió entonces, hoy cuenta con menos de la mitad. Con eso los atacameños regábamos más de mil hectáreas. Hoy MEL quiere sacar más de $1000 \mathrm{l} / \mathrm{s}$ de la macrocuenca del salar de Atacama, hacia sus faenas... MEL quiere agravar más la sequía en esta zona de alto riesgo ecológico" (COREMA 2007: 100).

Luego de estas expresiones le siguen otras fundamentaciones de carácter antropológica-jurídicas. Asimismo, se señalan otras protecciones como los humedales estipulados por el Convenio de Ramsar ${ }^{14}$ y en especial las modificaciones que se realizaron al Código de Aguas a fin de resguardar las vegas y bofedales altoandinos en la I y II región, a cargo de la Dirección General de Aguas. En definitiva, los argumentos se dirigen a cuestionar cómo MEL niega la territorialidad indígena, los derechos sobre sus recursos naturales y más aún, el no hacerse cargo de los impactos que su mismo estudio sostiene que generará el proyecto. Una serie de argumentos que buscan relativizar el carácter eminentemente "técnico" y por tanto "neutral" del EIA emanado de la empresa, así como cuestionar la política de buen vecino que dice establecer en su carta de principios citado en las ponderaciones recogidas. La resolución se constituyó en sí misma en un lugar de denuncias y cuestionamientos al Estado, sus compromisos y su rol de fiscalizador de las leyes. De la misma forma, la resolución se transformó en un espacio donde los agentes disputaron comprensiones sobre conceptos trascendentales como desarrollo, medioambiente, cultura, territorio, impacto, etc. Utilizando la misma jerga tecnicista de los órganos del Estado y la empresa privada, las organizaciones y comunidades indígenas contestaron con un discurso jurídico-antropológico de derechos indígenas, configurándose así en

${ }^{14}$ Convención relativa a los humedales de importancia internacional, especialmente como hábitat de aves acuáticas, firmada en la ciudad de Ramsar, Irán, en 1971. 
interlocutores válidos tan o más preparados para mostrar los vacíos de la legislación, las malas prácticas empresariales, así como una igual o mayor competencia para evaluar los impactos medioambientales, sociales, culturales y económicos de proyectos que se quieren desplegar en sus territorios. De un enunciado objetivo que propagaba el sistema de evaluación ambiental, la discusión y el debate se desplazó a cuestiones etnopolíticas que referían a temas de participación, así como formas de legitimación hasta ahora ignoradas y subordinadas dentro de la lógica de propiedad imperante en las legislaciones del Chile neoliberal. Este proyecto pareció configurarse como un catalizador de demandas históricas pendientes de las comunidades atacameñas del salar, mientras sus argumentos dirigidos a MEL parecieran traspasar fronteras y dirigirse al resto de las otras compañías así como al mismo Estado, calificado como ambiguo respecto al reconocimiento y protección de las poblaciones originarias. El dirigente socaireño que dirigió esta defensa recuerda con orgullo el significado de haberse enfrentado a la segunda minera más importante de Chile, así como el compromiso de las comunidades principales del sur del salar para movilizarse pese a no contar con los recursos ni técnicos ni materiales suficientes para emprenderla.

La serie de protestas y denuncias en las redes sociales sobre las deficiencias del proyecto fueron ratificadas por las evaluaciones técnicas de los organismos del Estado, quienes finalmente lo rechazaron: "Con catorce votos en contra y cuatro abstenciones, el día 24 de octubre la COREMA rechazó el proyecto de extracción de 1027 litros de agua por segundo que Minera Escondida pretendía usar en sus faenas" (Figura 2). Con estas palabras se celebró el triunfo de esta lucha en la prensa. En una carta pública, la comunidad de Toconao agradeció a quienes apoyaron esta causa advirtiendo el escenario inminente que vendría en el sector Géiseres del Tatio:

"Siempre tuvimos fe que mientras las comunidades estén unidas se podrá lograr detener el saqueo de nuestros recursos naturales, ya no estamos solos daremos la lucha por nuestros territorios y recursos naturales estamos dejando de ser comunidades desvalidas, estamos en procesos de fortalecimiento y crecimiento. Nótese que no estamos en contra del desarrollo y crecimiento de nuestro país, pero estamos convencidos que no será a costa de sacrificar nuestra cultura, nuestro ser de tiempos inmemoriables, de nuestra gentes y nuestra forma vida. Éste es un camino largo y tortuoso en contra de un Estado que sólo tiene leyes adversas y discriminatorias en contra de nuestro linaje indígena pero estamos aprendiendo a usar las armas del intelecto del pensamiento de los derechos humanos básicos y usaremos todo para defendernos de las mineras y transnacionales [...] El Tatio será nuestro próximo objetivo, otro proyecto que sólo pretende llevar crecimiento para unos pocos, a costa del riesgo de quitarnos el sustento turístico sustentable de todos nuestros hermanos de San Pedro de Atacama, indígenas y no indígenas de todas las comunidades del sur de Atacama, de las comunidades del Alto el Loa, que ven como una vez más intentan robarles el agua, el seno de un potencial turístico creado por el mismo Estado" (Fuente: blog licancabur).

Es tal la contemporaneidad de estos procesos, que casi en la misma fecha que sale la resolución de la COREMA favorable a las comunidades en contra del proyecto de Escondida, en octubre 2007, es que se interpone en la Corte de Apelaciones de Antofagasta una medida de protección para el Tatio ante los primeros movimientos realizados por la empresa durante el período de evaluación. No obstante, el conflicto del Tatio ${ }^{15}$ pese a producirse paralelamente a Pampa Colorada, mostró importantes diferencias. En el Tatio la solicitud de exploración geotérmica no provino de una empresa transnacional sino de una figura denominada "consorcio", compuesta por dos empresas nacionales, la Empresa Nacional del Petróleo -ENAP- y la Corporación Nacional del Cobre -CODELCO-, y la empresa multinacional ENEL. En otro punto, el Tatio implicó un involucramiento directo de la industria turística a partir de organizaciones loca-

15 El Tatio parecía un proyecto de larga data que el Estado chileno tenía hace décadas deseos de explorar. De hecho las primeras acciones para evaluar la capacidad geotérmica de esta zona las realiza CORFO en los años sesenta, con la construcción de un pozo que no prosperó. En medio, éste fue objeto de estudios que mostraban que era uno de los campos geotérmicos más grandes en Chile, por lo tanto un potencial para este tipo de energías. Probablemente por el alto costo de este tipo de energías es que hace unas décadas fue desestimado, pero se volvió a instalar con urgencia cuando Chile dio claras muestras de sus deficiencias energéticas, una vez que su consumo iba dirigido en más de un $80 \%$ al uso industrial, principalmente minero. De allí que en Chile se aprueba una ley de geotermia que impulsó numerosos proyectos a nivel nacional, la mayoría de ellos detenidos por la oposición de las comunidades indígenas tanto del norte como del sur del país. El proyecto en términos generales consistía en la construcción de cuatro pozos en un plazo de menos de un año. Proyecto cuya inversión se estimaba en unos 20 millones de dólares. 


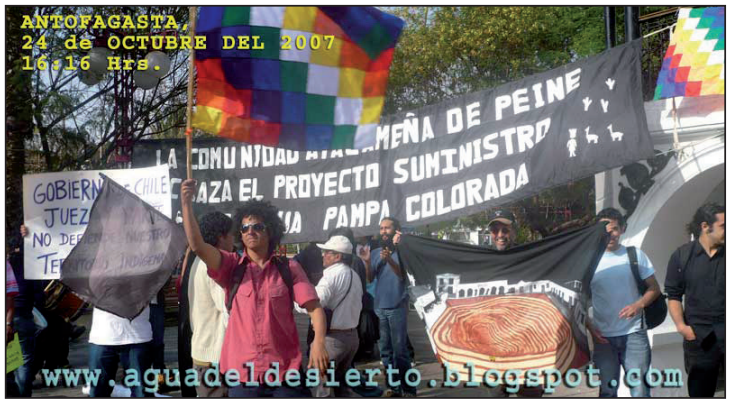

Figura 2. Manifestación contra el proyecto Pampa Colorada en la plaza de Antofagasta, 24 octubre del 2007 (Fuente: www. aguasdeldesierto.blogspot.com).

les como la Asociación Turística de Guías de San Pedro de Atacama -ATUSPA-, Asociación Turística y Medio Ambiente -ATYMA- y la Asociación de Empresarios de San Pedro de Atacama -AESPA-; las cuales vieron una clara amenaza al principal destino turístico de la región. Luego, este conflicto también mostró un involucramiento del aparato político partidario que ejerció presión a nivel del Congreso para rechazar el proyecto, principalmente con el apoyo de diputados y senadores que firmaron una carta de respaldo a las acciones realizadas por las comunidades y organizaciones locales. No obstante, éste se diluyó cuando el Ejecutivo no recibió a dos mujeres licanantay que caminaron en señal de protesta hasta la casa de gobierno. Esta acción, así como la participación de medios internacionales en la cobertura del conflicto, suscitó el interés de múltiples sectores del ámbito público y privado por colaborar en esta causa. Finalmente, el Tatio junto con representar el enfrentamiento directo entre las megaindustrias del turismo y la minería, significó una maduración respecto a las legislaciones indígenas y medioambientales ya incorporadas a partir del conflicto anterior. Esto se tradujo en un giro en las estrategias, que pasaron de la movilización como mecanismo de protesta en Pampa Colorada, hacia una judicialización de la problemática etnoambiental a partir del conflicto del Tatio.

Si bien este último proyecto, que iniciaba el acceso a las energías renovables no convencionales (ERNC) como la geotermia, buscaba diversificar la matriz energética y contribuir a superar la crisis energética de Chile, éste mostró nuevamente la débil estructura legal para proteger al medio ambiente, la cual previo pago de un seguro permitía a la empresa iniciar actividades mientras se rea- lizaba su evaluación. Como varios de sus protagonistas señalan, el Tatio no se hubiera detenido si no hubieran ocurrido los hechos de septiembre de 2009, cuando la empresa, iniciando su trabajo en un pozo ya construido en la década de 1960 por CORFO, generara una explosión en una de las fumarolas. Aunque previamente agentes locales habían constatado que se estaban realizando acciones sin las autorizaciones correspondientes, que estaban produciendo contaminación en aguas superficiales de la zona a partir de desechos de las faenas, el impacto que esta intervención generó no pudo ser borrado de la retina de quienes fueron testigos del evento. Frente a estos episodios se conformó la Mesa de Defensa del Tatio, dando inicio a una serie de acciones y reuniones que revelaron la experiencia ya alcanzada con Pampa Colorada, manifestándose en un buen manejo de elementos antropológico-jurídicos y técnico- ambientales, así como los referidos a la participación de las comunidades locales en estos procesos y su capacidad para evaluar proyectos. No obstante, el Tatio mostró que las relaciones entre comunidades indígenas y otros actores locales no indígenas no estaban resueltas del todo en el contexto local, y que pese a confluir en algunos momentos y bajo algunas condiciones como había sido en Pampa Colorada, éstas se vieron nuevamente confrontadas en un momento del conflicto del Tatio. Como uno de sus líderes nos recuerda:

"Nos faltó la habilidad de la comunicación, de ir a las bases, de conversar con cada una de las personas de las comunidades y no quedarnos solamente con el que se lo transmitimos y nos convencimos entre los dirigentes. En cambio lo otro fueron decisiones de la misma gente, la comunidad de Peine se juntó, la comunidad de Toconao, la comunidad de Socaire. Si las comunidades fueron las que se movilizaron, entonces acá a nosotros nos faltó eso, acá fue una cuestión, creo que fue algo más técnico y que la virtud que tuvo, como te digo y bueno y siempre dentro de las cuestiones más estratégicas es cómo uno a través de las estrategias va cambiando los escenarios. Nosotros decíamos este conflicto nosotros no lo podemos guardar para adentro, tenemos que abrirlo, todo el mundo tiene que saber que el Estado chileno quiere destruir el Tatio $y$ creo que de alguna forma lo conseguimos [...] porque al poco tiempo de empezar a plantearlo desde esa punta y ahí bueno ya no tenemos a las comunidades, perfecto, pero qué vamos a hacer, inos vamos a detener? 'Vamos a pararnos?iSigamos adelante! y ahí comenzamos a tratar de organizar una fuerza mucho más transversal. Ya no era la comunidad, las comunidades indígenas las que están, sino incluso con la cooperación del tour operador 
incluso se nos genera un conflicto con el resto de las comunidades indígenas y donde surge un espíritu, que es un espiritu desgraciadamente que está instalado en nuestras comunidades, creo que es de la desconfianza y obviamente tiene una razón... porque la desconfianza nace de que te han jodido muchas veces... Claro, entonces, las comunidades en vez de sentirse atraidas... se retraen más todavía, y por eso aparecen más tarde solamente, o sea no solamente sino mucha gente que no es indígena, tour operadores, pero no solamente habian tour operadores, había mucha gente... Yo en ese espacio conocí mucha gente linda fijate, que creo que sí en realidad les importa el territorio en el cual estamos y que quiere..., lo que está haciendo es defender su espacio y que ahí entendí también que nosotros los indígenas si bien llevábamos más tiempo viviendo acá, pero muchas veces como que nos olvidamos de la responsabilidad que tenemos con nuestra tierra. Pucha estamos, nos asumimos como pueblo, perfecto, pero en el momento de la lucha y la defensa tenemos que estar ahí y no esperar que venga otro y tome mi lugar, yo tengo mi lugar independiente si este otro esté de amarillo, rojo, yo tengo mi responsabilidad, y no pensar ah que éste, que este operador, si yo no me junto con éste, es una cuestión que creo que, desde mi punto de vista por supuesto, es con lo que juega también el sistema. Mientras más separaditos nos tenga mejor, son los indigenas, son los indigenas por favor no se junten con estos otros" (Entrevista a Tajniri, líder atacameño durante el conflicto del Tatio. San Pedro de Atacama, febrero 2012).

Estas expresiones mostraron la conformación de dos sectores, uno de carácter marcadamente ambientalista y turístico pero también apoyados por un sector de la dirigencia atacameña, mientras otro más indigenista y radical que buscaba recuperar el Tatio como una lucha eminentemente ancestral. Este mensaje fue el que quisieron hacer notar las dos mujeres que caminaron en defensa del Tatio desde San Pedro de Atacama hasta la capital (Figura 3), quienes en medio de su trayecto decidieron abandonar a un activo participante, que las acompañaba para cubrir mediáticamente el viaje. Ellas en orden de diferenciarse y mostrar que ésta era una defensa indígena de los licanantay, lo abandonaron a mitad del camino. No deseaban convertir al Tatio en una lucha política partidista ni sólo ambiental: estaban buscando recuperar el Tatio como cerro tutelar y malku sagrado más que un sitio turístico. Esta caminata de más de 2000 km, que terminó con el rechazo del Ejecutivo a recibir a estas dos mujeres, selló la impronta de una defensa con actores internamente distinguidos pero que actuaron externamente unificados, presionando a los organismos del Estado para que

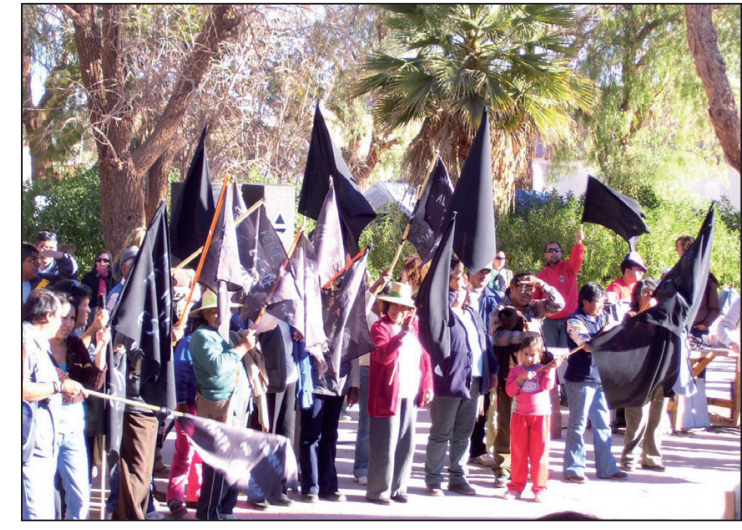

Figura 3. Manifestación en la plaza de San Pedro de Atacama contra el proyecto de exploración geotérmica en el Tatio.

el proyecto fuese detenido y posteriormente descartado. Pese a significar el Tatio un triunfo similar al experimentado tiempo antes con Pampa Colorada, éste dejó un sabor amargo por dos motivos: primero, porque mostró que las históricas divisiones entre atacameños y afuerinos no se encontraban zanjadas del todo; segundo, porque las viejas tensiones entre las comunidades del Alto Loa y las comunidades del salar se recrudecieron al punto que el Consejo de Pueblos Atacameños terminó dividido al final del conflicto. De una primera etapa marcada por el acuerdo entre comunidades de que esto afectaría a ambos sectores, las acciones de las empresas y el lobby del Estado para territorializar y localizar el conflicto en el sector del Alto Loa, tuvieron como consecuencias que estas comunidades decidieran salirse del Consejo de Pueblos Atacameños que hasta ahora había agrupado a ambas áreas. Finalmente y producto del desgaste y las acciones directas realizadas por la empresa con estas comunidades, es que logran que las comunidades de Toconce y Caspana -ambas coadministradoras del sitio Géiseres del Tatio- se hicieran presentes en el congreso y señalaran estar en desacuerdo con el rechazo al proyecto, así como contrarias al hecho de que las comunidades del salar asumieran el liderazgo del conflicto. La alegría del triunfo tuvo entonces un efecto divisorio amparado en la propia legislación indígena de los años noventa, que había introducido la idea de comunidades jurídicas independientes, rompiendo la idea de pueblos atacameños que hasta entonces venía conduciendo parte de la lógica de los acuerdos y colaboraciones entre comunidades indígenas al interior del Consejo de Pueblos Atacameños. Una de las protagonistas de esta cami- 
nata, quien también había apoyado en Pampa Colorada, resume lo aprendido con Pampa Colorada y el Tatio:

"Era más caro que sacar el agua que necesitan, por eso la empresa no apeló... Políticamente les convenía mucho que dijeran que las comunidades sintieran que habían ganado, pero en el fondo... fue que a la minera no le convenía porque era muy caro lo que le habian exigido... en medio ambiente, como devolver las aguas, de plata, por eso ellos no continuaron. Ese es un punto con Pampa Colorada, salía más cara la mitigación de lo que la minera pensaba realizar, siempre se lo han hecho sentir de que es así. Todos van a sacar partido de la situación. Cuando hay una lucha, causa, no siempre la causa es motivo de algo limpio y transparente, hay muchos intereses, en el caso del Tatio pasó lo mismo. Hubo un lado muy politico que se colgó de la causa, hay gente que sí sintió, luchó por el Tatio... el grupo del turismo era un interés económico como muy político... hemos aprendido mucho del sistema, somos muy politicos, o muy capitalistas, pertenecemos a este sistema neoliberal... Estuvo Caspana y Toconce capaces de viajar a Santiago al Senado y decir que aprobaran la geotermia... Ahí cuando tienes que ser muy estratégico, cuando estás en una causa, debes entender cuáles son los intereses que hay en esa causa... pero si tú tienes claro lo que te llevó a esa causa, eso se transforma en victoria. En Chile, no teníamos gobiernos los indígenas, quienes nos gobiernan son las transnacionales... El gobierno en ese momento queda en shock, su plan era otro, continuar con la geotermia, los mapuches estaban con seguridad del Estado... pero aquí del norte caminan dos mujeres en forma totalmente pacíficas... y no son recibidas. Ahí se dan cuenta que el mundo indígena no tiene ningún valor para el Estado de Chile. Chile lo toman como un país tropical... doble estándar... dices que tiene la ley indígena, que cumple con todas las normas..." (entrevista a Sonia Ramos, dirigente atacameña. San Pedro de Atacama, febrero de 2012).

Lo cierto, es que estos dos episodios dejaron una huella no sólo en sus protagonistas sino también en las instituciones jurídicas, marcando un precedente histórico. Éstos, sin embargo, fueron motivo de gloria por poco tiempo, ya que dos años más tarde se conocen en el salar las doce adjudicaciones geotérmicas que realizó el gobierno de Sebastián Piñera vía decretos a diversas empresas transnacionales y nacionales. Estos proyectos emanados desde el Ministerio de Energía involucraban exploraciones geotérmicas en casi toda la precordillera, lo cual nuevamente levantó la acción de las organizaciones locales en un contexto de elección de alcaldes y consejeros municipales. Estos hechos, junto a la aprobación de un decreto para licitar internacionalmente las áreas protegidas silvestres del Estado (SNASPE) y el inicio tempranamente abortado de la licitación del litio, pusieron a las comunidades atacameñas del salar nuevamente en situación de alerta. Aunque ninguno de estos proyectos prosperó, en parte por los recursos de protección que el Consejo de Pueblos Atacameños interpuso en la corte de apelaciones, estos revivieron un clima de tensión muy similar a los vividos anteriormente con Pampa Colorada y el Tatio, obligando al Estado y las empresas a repensar sus estrategias de relación y comunicación en el salar. Estas acciones terminaron por presionar al Estado para que bajara sus expectativas respecto a su política energética, generando explícitas molestias desde el sector privado por las inversiones detenidas, situaciones que -declararon- "amenazan al desarrollo de Chile". Propuestas que hasta ahora no han querido avanzar por el sistema de evaluación ambiental, el cual hoy además se encuentra objetado por las comunidades indígenas nacionales ante instancias internacionales, señalando que su reglamento no respeta el derecho a la consulta previa e informada exigida por el Convenio 169 que Chile ratificó el 2008. Nos encontramos en consecuencia, ante un escenario dinámico e impredecible, que transita simultáneamente por estrategias de oposición y rechazo vía judicialización, como también por canales de negociación expresados en convenios firmados y programas colaborativos entre empresas y comunidades en el salar.

\section{* La (in)sostenibilidad del salar de Atacama. A modo de cierre}

Los conflictos etnoambientales de Pampa Colorada y el Tatio configuraron un escenario de transición hacia la era postmulticulturalista en la región del salar. Éstos fueron capaces de incorporar tanto elementos medioambientalistas/conservacionistas propios de algunos movimientos antiglobalización, como también demandas étnicas pendientes que relevaron estas luchas como estrategias de recuperación y control territorial entre las comunidades atacameñas del salar. Estas luchas asimismo se desplegaron en un contexto de cierre del período indigenista/multicultural y patrimonial impulsado por el Estado democrático, iniciando una nueva comprensión de los derechos indígenas y del patrimonio natural y cultural bajo el contexto de ratificación del Convenio 169 en el 
año 2008. Un período en el que paralelamente comenzó a tomar forma y contenido la política energética que se promulgó el año 2000, la cual buscó impulsar un desarrollo de energías no convencionales como la geotérmica, en un contexto de crecimiento de la demanda energética y en particular de la hídrica por la expansión de la industria minera en el norte de Chile. Estas luchas pusieron a su vez en cuestionamiento los mecanismos de participación de las comunidades locales -indígenas y no indígenasafectadas por las políticas neoliberales intensificadas en las últimas décadas en la región, los cuales mostraron dificultades para cumplir los compromisos señalados en la legislación indígena y medioambiental nacional, como también los de carácter internacional que declararon al salar como un ecosistema frágil y con una biodiversidad rica necesaria de resguardar.

Estos hechos, en definitiva, pusieron al descubierto las viabilidades o inviabilidades de compatibilizar derechos indígenas dentro una lógica de mercado, a su vez revelaron los efectos no esperados de una política cuyas pretensiones de limitar las formas de participación y de control sobre el territorio fueron contestadas a través de acciones como las banderas negras en las casas de las comunidades atacameñas y la caminata de dos mujeres licanantay a la sede de gobierno. El mensaje sobre la muerte inminente de la vida en el salar y de su cultura, inundó los rostros y las expresiones durante ese período. Este escenario se configuró en un contexto paradigmático, capaz de contener a un sector contrario a proyectos mineros y geotérmicos que se refugió en el turismo como estrategia de sobrevivencia y mecanismo de defensa de su patta hoiri (madre tierra en lengua kunza), así como otro sector dispuesto a establecer convenios y contratos "regulados"a fin de recibir compensaciones. Ambos, no obstante revelaron una articulación hasta hace poco inexistente en el salar entre comunidades indígenas y no indígenas, que aunque tuvo una corta duración, reveló cada vez mayores grados de conciencia y capacidad para contestar procesos de globalización transnacional como los experimentados en el último período en el salar.

El paso al siglo XXI se erigirá entonces como un período especialmente de contrastes y paradojas en esta área que se promueve al mismo tiempo como una región indígena, minera y turística. Mientras se propagan discursos de responsabilidad social empresarial en torno a la sustenta- bilidad y el desarrollo local en un escenario de relaciones de buen vecino entre comunidades y empresas, se observa una maduración de los procesos de diferenciación socioétnicos iniciados en los años noventa, los cuales fueron arribando a objetivos múltiples, tanto de incorporación en los mercados transnacionales de la minería y el turismo, como de posicionamiento sociopolítico capaz de influir en los caminos de un desarrollo más autónomo y participativo en el territorio. En este sentido, la cultura y la identidad se constituyeron en un recurso económico y político, a la vez que simbólico para las comunidades atacameñas, que les permitió legitimarse como los principales agentes en el salar de Atacama.

Los hechos de Pampa Colorada y el Tatio mostraron por primera vez el enfrentamiento directo entre las megaindustrias de la minería y el turismo, las cuales pusieron en jaque los discursos y prácticas corporativas asociadas a la protección del medio natural y cultural atacameño. Las acciones desplegadas por las corporaciones mineras dirigidas a potenciar políticas e imaginarios de indígenas empresarios e innovadores, fueron reconvertidas por las comunidades atacameñas y otros grupos no indígenas hacia objetivos que apuntaban a satisfacer demandas tanto étnicas como medioambientales. Éstas abrieron un escenario de luchas en las comunidades por recuperar sus recursos tanto naturales como culturales en condiciones políticas y organizativas débiles, pero fortalecidas por redes e instancias nacionales y trasnacionales alternativas. La propia Corporación Nacional de Desarrollo Indígena en estos últimos años recibió críticas y cuestionamientos al conformarse como servicio público, abandonando su rol de garante de los derechos indígenas consagrados en la Ley 19.253. Institución que, aunque cumplió su deber de presentar sus objeciones en los estudios de impacto ambiental en el caso de ambos proyectos, fue incapaz de frenar las múltiples solicitudes de derechos de aprovechamientos de agua y de concesiones mineras y geotérmicas que se otorgaron sin restricciones durante este período y el siguiente, en toda la zona precordillerana del salar.

Las organizaciones y comunidades locales, luego de algunos años de respirar un aire optimista por estas luchas que parecían ganadas, vieron con las adjudicaciones geotérmicas del 2011 y 2012 que no estaba todo dicho y rápidamente reaccionaron y mostraron su descontento. Éste se manifestó con la interposición de múltiples re- 
cursos de protección contra el ministro de Energía. No obstante, el camino de la judicialización iniciado con el Tatio y retomado con las adjudicaciones geotérmicas recientes, no se contradice con las acciones de las comunidades en pos de alcanzar diálogos y negociaciones directas y efectivas con las empresas por la vía de convenios y programas. Entienden cada vez más que así, tal como en determinados momentos y bajo ciertas condiciones son necesarias la movilización y la oposición, también es necesario desplegar estrategias de vinculación y cooperación en pos de su supervivencia concreta en el salar. Éstas son hoy las disyuntivas de una globalización transnacional impuesta y resistida, confrontada y negociada, así como también rearticulada en torno a fines múltiples en contextos cambiantes, donde tanto agentes locales -indígenas y no indígenas-, regionales, nacionales y trasnacionales, están permanentemente intentando renovar sus discursos, prácticas y estrategias a objeto de asegurar su lugar y su poder dentro del complejo paisaje social y cultural del salar.

Agradecimientos A los líderes atacameños y no atacameños que participaron en los hechos de Pampa Colorada y el Tatio, en especial a Antonio Cruz, Tajniri, Oriana Mora, Sonia Ramos, Carolina Albornoz, Verónica Moreno, Lorena Ulloa, así como a la abogada Nancy Yáñez y al geógrafo e historiador Raúl Molina quienes me entregaron su tiempo y valiosos documentos de ese período. Agradezco también a los evaluadores de este trabajo, que ofrecieron importantes luces para mejorarlo y a FONDECYT por su apoyo a través del proyecto postdoctoral 3120062 del cual es parte este artículo.

\section{$*$ Referencias citadas}

ÁlVAREZ, B. 1998 [1588]. De las costumbres y conversión de los Indios del Perú. Memorial a Felipe II. Ediciones Polifemo, Madrid.

AYALA, P. 2007. Relaciones entre atacameños, arqueólogos y estado en Atacama (norte de Chile). Estudios Atacameños:Arqueología y Antropología surandinas 33: 133-157.

BABIDGE, S. 2013. "Socios": The Contested Morality of "Partnerships" in Indigenous Community-Mining Company Relations, Northern Chile. Journal of Latin American and Caribbean Anthropo$\log 18(2): 274-293$.

BECK, U. 1998. ¿Qué es la globalización? Falacias del globalismo, respuestas a la globalización. Paidós, Barcelona.

BIBAR, J. 2001 [1558]. Crónica de los Reinos de Chile. Dastin Historia, Madrid.

BOCCARA, G. 2000. Antropología diacrónica. Dinámicas culturales, procesos históricos y poder político. En Lógica mestiza en América, G. Boccara y S. Galindo (Eds.), pp. 21-59. Instituto de Estudios Indígenas, Universidad de la Frontera, Temuco.

BOCCARA, G. y P. AYALA. 2011. La nacionalización del indígena en tiempos de multiculturalismo neoliberal. IAS journal 4(2). En www.interamerica.de/volume-4-2/boccara_ayala/

BOCCARA, G. e I. SEGUEL. 1999. Política indígena en Chile (siglos XIX y XX). De la asimilación al pluralismo. Revista de Indias 217(LIV): 741-774.
BOLADOS, P. 2010. Neoliberalismo multicultural en el Chile democrático: gubernamentalizando la salud atacameña a través de la participación y el etnodesarrollo. Tesis doctoral en antropología. Universidad Católica del Norte y Universidad de Tarapacá, San Pedro de Atacama.

BOURDIEU, P. y L. WACQUANT. 2005. Una invitación a la sociología reflexiva. Siglo XXI, Argentina y México.

BUSTOS, A. 2005. Hacia un turismo intercultural: el caso atacameño. Revista LÍDER 13(10): 133-150.

BUSTOS, C., M. CRUZ y C. YUFLA. 2012. Turismo comunitario y patrimonio en el desierto de Atacama. Revista América Patrimonio 4. En http://www.revistaamericapatrimonio.org/

CHILE SUSTENTABLE 2010. 2010. Conflictos por el agua en Chile: entre los derechos humanos y las reglas del mercado. S. Larraín y P. Poo (Eds.). Chile Sustentable, Santiago de Chile.

CARRASCO, A. 2011. One world, many ethics. The politics of mining and indigenous peoples in Atacama, Chile. Tesis doctoral. Universidad de Arizona, Arizona.

CASTELLS, M. 2005. Globalización, desarrollo y democracia: Chile en el contexto mundial. Fondo de Cultura Económica, Santiago de Chile.

COMISIÓN CHILENA DEL COBRE. 2010. Anuario de estadísticas del cobre y otros minerales. Yearbook: Copper and other Mineral statistics. COCHILCO, Santiago. http://www.cochilco.cl/productos/descarga/anuarios/anuariozolo.pdf (consultada el 1 de enero de 2013). 
Corporación Regional del Medio Ambiente (COREMA). Resolución de Calificación Ambiental "Proyecto Pampa Colorada". Resolución Exenta 0366/2007. Antofagasta.

CONGRESO NACIONAL DE LA REPÚBLICA DE CHILE. 1993. Ley 19.523. Sobre protección, fomento y desarrollo de los indígenas.

1994. Ley 19.300. Bases Generales del Medio Ambiente.

2000. Ley 19.657. Ley sobre Concesiones Geotérmicas.

2001. Reglamento del Sistema de Evaluación de Impacto Ambiental.

COMAROFF, J. y J. COMAROFF. 2009. Etnicithy Inc. The University of Chicago Press, Chicago.

FLORA Y FAUNA CHILE LDTA. s/f. Estudio línea base y guía de manejo del predio Puritama, Región de Antofagasta. Santiago de Chile.

HARVEY, D. 2008. La condición de la postmodernidad: investigación sobre los orígenes del cambio cultural. Amorrortu, Buenos Aires.

HIDALGO, J. 2004. Historia andina en Chile. Editorial Universitaria, Santiago de Chile.

MARCUS, G. 1995. Ethnography in/of the world system: the emergence of multi-sited ethnography. Annual Review of Anthropology 24: 95-117

MARTINEZ, J.L. 1998. Los pueblos del chañary el algarrobo. Los Atacamas en el siglo XVII. DIBAM, Santiago de Chile.

MATO, D. 2000. Des-fetichizar la 'globalización': basta de reduccionismos, apologías y demonizaciones; mostrar la complejidad y las prácticas de los actores. Grupo de Trabajo "Globalización, Cultura y Transformaciones Sociales" del Consejo Latinoamericano de Ciencias Sociales (CLACSO), pp: 147-177, Caracas.

2004 Redes transnacionales de actores globales y locales en la producción de representaciones de ideas de sociedad civil. En Políticas de ciudadanía y sociedad civil en tiempos de globalización,
D. Mato (Ed.), pp: 67-93. Universidad Central de VenezuelaFACES, Caracas.

MINISTERIO DE JUSTICIA, 1981. DFL 1122. Fija Texto del Código de Aguas. Biblioteca del Congreso Nacional, Santiago de Chile.

MINISTERIO DE MINERÍA. 1982. Código de Minería. Biblioteca del Congreso Nacional, Santiago-Chile.

MURRA, J. 1996. El control vertical de un máximo de pisos ecológicos y el modelo del archipiélago. En Comprender la agricultura campesina en los Andes centrales, P. Morlon (Comp.), pp. 122-154. IFEA-CBC, Lima/Cuzco.

NÚÑEZ, M. 2002. Transformaciones culturales en Toconao por impacto de empresas mineras: un estudio de caso en el norte de Chile. Tesis de magíster en Antropología. Universidad de Chile, Santiago de Chile.

RIDES. 2005. Evaluación Ecosistémica del Milenio: Bienestar Humano y Manejo sustentable en San Pedro de Atacama-Chile. Resumen Ejecutivo. ONG Corporación RIDES, Santiago de Chile.

RIVERA, F. 2007. Entorno neoliberal y la alteridad étnica antiflexible de los atacameños contemporáneos. Revista de Antropología 18: 59-89.

SANHUEZA, C. 2001. Las poblaciones de la Puna de Atacama y su relación con los Estados nacionales. Una lectura desde el Archivo. Revista de Historia Indígena 5: 55-82.

SERNAGEOMIN. 2010. Anuario de la Minería de Chile. En http:// www.sernageomin.cl/pdf/mineria/anuario_2010.pdf (consultada el 1 enero de 2013).

TAGLIOLINI, B. 2010. Le tourisme comme stratégie: les politiques locales, nationales et internationales dans le village de San Pedro de Atacama au Chili. Tesis de magíster. CNRS-EHEES, Francia.

YÁÑEZ, N. y R. MOLINA. 2008. La gran minería y los derechos indígenas en el norte de Chile. LOM ediciones, Santiago de Chile.

YÚDICE, G. 2008. El recurso de la cultura. Usos de la cultura en la era global. Gedisa, España. 